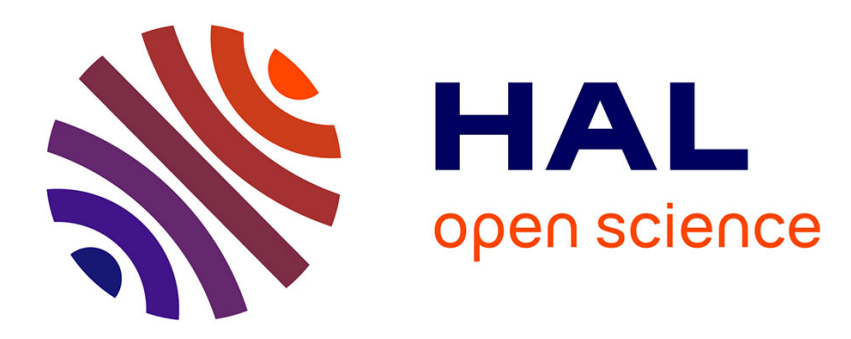

\title{
Explaining Opposition to Turkish Membership of the EU
}

Lauren M. Mclaren

\section{To cite this version:}

Lauren M. Mclaren. Explaining Opposition to Turkish Membership of the EU. European Union Politics, 2007, 8 (2), pp.251-278. 10.1177/1465116507076432 . hal-00571745

\section{HAL Id: hal-00571745 \\ https://hal.science/hal-00571745}

Submitted on 1 Mar 2011

HAL is a multi-disciplinary open access archive for the deposit and dissemination of scientific research documents, whether they are published or not. The documents may come from teaching and research institutions in France or abroad, or from public or private research centers.
L'archive ouverte pluridisciplinaire HAL, est destinée au dépôt et à la diffusion de documents scientifiques de niveau recherche, publiés ou non, émanant des établissements d'enseignement et de recherche français ou étrangers, des laboratoires publics ou privés. 


\section{EUP}

European Union Politics

DOI: $10.1177 / 1465116507076432$

Volume 8 (2): 251-278

Copyright@ 2007

SAGE Publications

Los Angeles, London, New Delhi and Singapore

\section{KEY WORDS}

- enlargement

- Europe

- multi-level modelling

- public opinion

- threat

- Turkey

\section{Explaining Opposition to} Turkish Membership of the EU

\section{Lauren M. McLaren}

University of Nottingham, UK

\section{ABSTRACT}

This article examines EU citizen attitudes to Turkey's bid to join the EU. The key theoretical constructs investigated to explain opposition to Turkey's EU membership are related to rational economic self-interest and group-level interests and concerns. The findings indicate that the former are irrelevant for distinguishing between opponents and supporters of Turkey's candidacy, while the latter do provide fairly powerful explanations for opposition to Turkish EU membership. However, because these factors do not completely explain overall levels of hostility to Turkey's candidacy, context is also introduced, particularly the threatening context provided by Turkish migration. The findings indicate that migration from Turkey to some of the EU member states has combined with feelings of group protectiveness to produce widespread animosity to Turkey's entry into the EU. 
Turkish entry into the European Union (EU) is a highly contentious issue. As the country continues to make political and economic reforms in the hopes of being granted a definite entry date, it appears quite possible that the country's admission into the EU could be halted by EU citizens, regardless of what decision their leaders reach with respect to Turkey's membership. The French debate surrounding the (failed) referendum on the European Constitution, in which some of the public argued that the referendum could be used as a vote against Turkey's candidacy, is only one indication of the virulence of opinion regarding this particular candidacy. As with many important EU policy decisions (e.g. those outlined in the Constitutional Treaty and the Treaty on European Union), it is possible that EU citizens themselves will make the final decision on whether Turkey is allowed to join the EU. Because of the high degree of citizen relevance to this particular decision, it is important that mass opinion regarding the Turkish candidacy is analysed. This is the purpose of this article.

Turkey first became affiliated with the EU in 1963 after signing an associate membership agreement with the then European Community (EC). Although the country might have taken the opportunity to apply for full EC membership at the same time that Greece applied in 1975, its leaders failed to do so, citing the need to develop further economically before gaining full entry to the EU (Eralp, 1993; Müftüler-Baç, 1997). It was not until the EC was in the midst of an already difficult Southern Enlargement that Turkey lodged its application for full EC membership (in 1987). This is also the first point at which we gain some indication of the feelings of the European mass public on the issue of Turkey joining the EU. Shortly before the Turkish application was lodged, a Eurobarometer poll conducted in the Spring of 1986 asked respondents the following: 'Supposing Turkey asked to be admitted as a member country of the European Community (Common Market). What would be your opinion?' Even at this early stage, support was not overwhelming: approximately $20 \%$ of EC citizens were favourable to this idea and about $30 \%$ were opposed; the rest of the public was indifferent. In what might now be seen as a sign of things to come, France displayed the greatest opposition, after Greece, to the idea of Turkey joining the EU. Still, slightly less than $50 \%$ in France and exactly 50\% in Greece were opposed. Since the late 1990s, overall opposition to Turkey's candidacy has remained close to $50 \%$ (for instance, opposition was at $47 \%$ in the autumn of 1999 and $49 \%$ in the autumn of 2002). Table 1 indicates that, in comparison with other countries that were official candidates for EU membership prior to 2004, opposition to Turkey's candidacy has consistently been the strongest. Table 2 provides levels of opposition to Turkey's candidacy by EU member state, and indicates that there are vast differences across EU member states regarding feelings about Turkey's candidacy. 
Table 1 Opposition to EU candidacies (\%)

\begin{tabular}{lllll}
\hline & 1999 & 2000 & 2001 & 2002 \\
\hline Malta & 26.5 & 28.0 & 28.0 & 29.0 \\
Hungary & 31.0 & 31.5 & 30.0 & 30.5 \\
Cyprus & 33.0 & 33.5 & 33.0 & 33.5 \\
Poland & 34.5 & 35.0 & 34.0 & 34.5 \\
Czech Republic & 35.0 & 35.5 & 34.0 & 34.0 \\
Estonia & 38.0 & 38.0 & 38.0 & 37.0 \\
Latvia & 38.0 & 38.0 & 38.0 & 37.5 \\
Slovakia & 38.5 & 38.5 & 38.0 & 37.5 \\
Lithuania & 39.0 & 38.5 & 38.0 & 37.5 \\
Bulgaria & 39.5 & 40.5 & 40.0 & 40.0 \\
Slovenia & 41.5 & 40.5 & 40.0 & 40.0 \\
Romania & 42.5 & 43.5 & 43.0 & 44.0 \\
Turkey & 47.0 & 47.5 & 46.0 & 48.0 \\
& & & & \\
\hline
\end{tabular}

Notes: All percentages are from Eurobarometer surveys (EB 51-58); other than 2001, all percentages are an average across two surveys conducted in the same year. Note that the differences in percentages between any two semi-annual surveys is minimal, however.

Table 2 Opposition to Turkish candidacy by member state (\%)

\begin{tabular}{llr}
\hline & $\%$ Opposed & \\
\hline Spain & 23 & 964 \\
Ireland & 26 & 967 \\
Portugal & 30 & 920 \\
United Kingdom & 35 & 1217 \\
Italy & 45 & 959 \\
Sweden & 46 & 949 \\
EU average & 47 & 14,750 \\
Netherlands & 49 & 838 \\
Greece & 51 & 951 \\
Denmark & 52 & 944 \\
Germany & 55 & 1904 \\
Belgium & 56 & 942 \\
France & 56 & 878 \\
Finland & 57 & 949 \\
Austria & 63 & 898 \\
Luxembourg & 66 & 470 \\
\hline
\end{tabular}

Note: The percentages are based on Eurobarometer 53 (Spring 2000), the survey to be used for most of the analyses in this article; note that the percentages change very little for each of the member states across the 1999-02 period. 
The purpose of this article is to explain contemporary hostility to Turkey's EU membership amongst citizens of the EU. In developing possible explanations for variation in this hostility, it turns to theoretical propositions that have their roots in rational self-interest and group interest. The article also incorporates analyses of attitudes toward other candidacies in order to determine the degree to which the explanations investigated account for opposition to Turkish membership in particular. The question posed at this stage of the analysis is: do our chosen explanations for this hostility provide any explanation for why EU citizens feel so strongly about Turkey? The findings indicate that - somewhat surprisingly - they do not uniquely explain hostility to the Turkish candidacy. Therefore, the role of national context is introduced as a possible explanation for negative reactions to Turkish EU membership. The general argument is that, although group interests and fears related to threats to these interests provide some understanding of hostility to Turkey, these explanations are also valid in understanding opposition to other candidacies. The key difference lies in the threatening context provided by high levels of immigrants. That is, in countries where immigration from Turkey is high, citizens are most hostile to the Turkish candidacy. These results are also contrasted with those from other candidate countries that have been the sources of large-scale immigration, particularly Poland. The key conclusion drawn from the analysis is that, although factors such as cultural threat may be important for explaining hostility to Turkey's candidacy, they are equally important for explaining hostility to other candidates and that the key problem for Turkey's candidacy is long-term, large-scale migration. Instead of creating a climate of empathy for the country of origin of these migrants, high levels of Turkish migration have created a climate of perceived threat to in-group resources and culture that manifests itself partly as opposition to Turkey's candidacy for EU membership.

\section{Explaining opposition to Turkey's candidacy: Theoretical perspectives}

There are several strands of academic literature that help to explain why some EU citizens are opposed to the idea of Turkey entering the EU while others are more favourable. First is the general body of literature on public opinion regarding government policies, as well as the general literature on voting behaviour. Both of these tend to present at least two contrasting hypotheses about the nature of opinion formation and political behaviour: the selfinterested approach and the group-interest, or sociotropic, approach. The findings in these literatures indicate that at times self-interest motivates 
opinions, attitudes and behaviours whereas, at other times, more general perceptions about the needs of society seem to be a motivation. Academic literature on attitudes to the European integration process also incorporates very similar themes. Moreover, as will be seen below, this paper conceives opposition to Turkey's EU candidacy as being strongly connected to feelings about in-groups and out-groups, implying that literature on prejudice is relevant as well. Not surprisingly, this literature also tends to contrast the role of self-interest versus group-interest. The latter literature further points to the importance of a threatening environment in explaining why some citizens are more prejudiced than others. Each of these themes is outlined below and applied to the context of the Turkish candidacy.

\section{Rational economic self-interest}

One of the key propositions in research on public opinion and mass political behaviour is that these are based on individual self-interest: people have differing feelings regarding public policies because those policies affect their personal lives in different ways. This approach has already been applied in a great number of studies of attitudes to European integration and should be similarly applicable to the case of enlarging the EU to include Turkey.

In general terms, the rational egocentric argument found in the literature on European integration is that EU citizens perceive European integration through the lenses of how integration will affect them personally. Many of these effects are said to be economic or financial, in that opponents of integration are hostile to the project because it has caused them (or will cause them) some financial harm. The economic policies adopted in the EU, especially since the Single European Act, are argued to impose clear economic costs and benefits on EU citizens: the free movement of labour and capital provisions, as well as the increased possibility for business to move from one to another of the EU member states, mean that companies can go freely to where they find cheaper labour (and continue to benefit from EU-wide business regulations) or cheaper labour can come to them, providing competition for EU citizens who do certain types of work. Those with lower-level job skills and at the lowest income levels are thought to be potentially most hard-hit because they are more easily replaceable by companies moving elsewhere or hiring migrant workers (see Anderson, 1998; Anderson and Reichert, 1996; Brinegar and Jolly, 2005; Cichowski, 2000; Gabel, 1998a, 1998b; McLaren, 2006; Mahler et al., 2000; Markowski and Tucker, 2005; Slomczynski and Shabad, 2003).

The same sort of competition pressures should apply if Turkey joins the EU. Those who are already weakest in the EU market - those with low incomes and who perform manual labour - should be the most fearful of 
Turkey joining the EU. It can be argued that, with Turkey as a full EU member, businesses in current EU member states will be encouraged to move to that country to seek lower costs in the form of cheaper wages. ${ }^{1}$ Moreover, EU citizens are likely already to have the impression that poor, unskilled Turks are willing to migrate to the EU to find work (given that so many have done so - see Ahtisaari et al., 2004) ${ }^{2}$ and thus, once again, we would expect those at the lowest income and job levels to be the most worried about the prospect of Turkey joining the EU as a full member. In addition, it is expected that farmers will be amongst the least supportive of the Turkish candidacy for similar reasons: the Turkish agricultural sector is still relatively large, comprising approximately $50 \%$ of all employment in the country and approximately $15 \%$ of GDP and exports (US State Department, 2005). Thus, concern about competition for agricultural sales and subsidies with regard to Turkish entry into the EU is likely to be particularly high amongst EU member state farmers.

\section{Perceived threats to in-groups}

Other research on public opinion and political behaviour indicates that public perceptions of policy and citizen behaviour are not necessarily driven by the rational self-interest described above (see Funk and Garcia-Monet, 1997; Kinder and Kiewiet, 1979; Mansbridge, 1990; Sears and Funk, 1990). In some cases, it is only when respondents are prompted to think about a particular issue within the context of their own circumstances that personal self-interest translates into support for or opposition to a policy (Chong et al., 2001; Sears and Lau, 1983). This is likely also to be true in the case of perceptions of the Turkish EU candidacy. Thus, with respondents having very little specific information about the way that Turkey's entry into the EU will affect them personally - particularly their economic livelihoods - what would we expect to serve as the basis of differing opinions regarding this candidate? I contend that the main basis on which Turkey's candidacy is perceived is in terms of group interest. EU citizens may not have a clear idea of how this particular enlargement will affect their own economic position but they are likely to have some idea of how it will impact others like them, or their key in-groups. I assume here that one of the key in-groups is the nation or nationality, although I acknowledge that studying perceptions of other in-groups may be equally applicable. ${ }^{3}$

There are several reasons for turning to perceptions of the effects of policies on the in-group. First, research on economics and elections has long illustrated the importance of group-level concerns. In models that include pocketbook and sociotropic economic indicators (the former consisting of measures of concern about one's personal economic situation and the latter 
measuring feelings about the national economy), it is the latter that appear to predict voting behaviour most consistently (Kinder, 1981; Kinder and Kiewiet, 1979; Lewis-Beck, 1988). That is, choices between government officials appear to be far more consistently driven by perceptions about how candidates will influence the economic prospects of the country as a whole, with personal pocketbook considerations often playing a minimal or nonexistent role. In this case, it may be that individuals have difficulty determining how an election outcome will affect their own pocketbooks and instead turn to an analysis of the election's impact on their fellow citizens. Similarly, research on attitudes to the welfare state and healthcare policy in Europe indicates that these attitudes tend to be driven far more by sociotropic concerns than by individual-level self-interest (Gelissen, 2000; Gevers et al., 2000). A similar process is likely to occur in the context of contemplating the Turkish candidacy: EU citizens may not be clear about how this candidacy will affect their pocketbooks, and so they consider the candidacy in terms of its impact on their fellow citizens instead.

Second, Turkey is not likely to be seen simply as a holistic, organic nationstate and global politics player. In contrast to the way that many EU officials might treat the country - in terms of its level of democracy, economic development, etc. - EU citizens are likely to see it also in terms of the people who constitute the country (i.e. Turks). Perceiving EU enlargement not just in the context of the country that will be adopted into the EU but also in terms of the new citizens who will join the EU renders an in-group focus even more relevant. This is because rejection of the Turkish candidacy may be more about rejection of Turks as a group of people than about rejection of the country in abstract terms.

Conceptualizing enlargement in this way means that explanations for differences in opinion about the Turkish candidacy are likely to relate to outgroup rejection and its counterpart, in-group identity and protectiveness. The social psychology literature points to at least two different aspects of protectiveness: those connected to the group's resources and those related to important symbols, customs and myths that the group holds to be important. What threats do Turks and Turkey pose to these group elements, though?

If Turkey is perceived as consisting of Turks, the prospect of enlargement presents a very similar dilemma to that of immigration from Turkey - a point also mentioned in the above discussion of rational economic self-interest and so the threats to the in-group presented by Turks should be similar to perceived threats presented by immigrants and other minorities in general. Specifically, immigrants and minorities are often seen as posing a threat to the jobs of natives or non-minorities and to the social security resources of the host country (see Citrin et al., 1997; Bobo, 1988; LeVine and Campbell, 
1972; Quillian, 1995). Moreover, such perceptions often exist regardless of the degree of personal vulnerability to job loss or dependence on social security benefits (see Citrin et al., 1997). Given that modern Turkey is a country of emigration that has traditionally sent its poorer citizens to work in EU member states (as discussed above), it would seem very likely that EU citizens perceive this candidacy as a strong potential threat to group resources such as social security benefits and jobs.

It is not just the threat to resources presented by Turks that should affect feelings about the Turkish candidacy; threats to culture and way of life (sometimes termed 'symbols' in social psychology literature) are likely to be particularly strong in the Turkish case (see Ivarsflaten, 2005; Sears et al., 1979; Sniderman et al., 2004). In addition to the possible problem of being perceived as traditional and/or backward, Turkey faces the obvious potential difficulty of being predominantly Muslim. Because of these perceived differences between Turkish and European cultures, feelings about this particular candidate may be strongly connected to concerns about the maintenance of the culture and way of life of key in-groups. Furthermore, if - as some contend (see Müftüler-Baç 2000) - feelings about Turkey's candidacy are predominantly motivated by fears related to culture and religion, we would expect these fears to be far stronger in predicting attitudes to Turkey's candidacy vis-à-vis attitudes to other candidacies.

\section{Context}

As shown in the introduction, opposition to Turkey's candidacy is consistently higher than opposition to any other pre-2004 candidacy. Moreover, the level of opposition varies considerably by EU member state. Although it is entirely possible that the individual-level explanations discussed above account for both of these phenomena, it seems more likely that contextual explanations must be introduced. Because of the large differences across EU member states in levels of opposition to Turkey's candidacy, I assume in this article that the country-level context is relevant. Which aspects of context are important for explaining feelings about Turkey's candidacy, though?

One potential contextual explanation stems from the economic selfinterest and group-interest approaches. Namely, attitudes to European integration and attitudes to EU enlargement have both been conceived as being connected to the trade benefits received from the process of European integration (Eichenberg and Dalton, 1993; Jones and van der Bijl, 2004). As applied to the Turkish candidacy, EU member states do not receive much in the way of trade benefits from Turkey, and so citizens are generally 
more strongly opposed to this country's candidacy than to other EU candidacies.

Other potential contextual variables include the degree of poverty of the candidate country. Also in line with the economic interest approach, it may be argued that citizens of EU member states should be more hostile to the poorer of the EU candidates because their addition to the EU will very likely mean increased financial support - in turn implying that EU citizens themselves will be forced to subsidize the new member state economies. However, analyses by Karp and Bowler (2006) indicate that a candidate's GDP per capita has little impact on support for or opposition to that particular candidacy (see also Jones and van der Bijl, 2004).

Another contextual argument in literature on attitudes to enlargement revolves around the notion of geographical proximity. Jones and van der Bijl (2004) contend that greater geographical proximity promotes a stronger 'we-feeling' between the candidate and the member state. Thus, the greater the geographical proximity, the greater the support for a candidate country.

Besides these contextual factors, I contend that, given the potential for cultural and resource-based threats discussed above, the context presented by Turkish migration may explain the relatively large degree of hostility to this particular candidate. In contrast to other candidate countries, Turkey has been a major source of large-scale migration to Europe since the end of the Second World War, with the highest concentrations of Turks residing in Germany, France, the Netherlands, Austria and Belgium (Ahtisaari et al., 2004; see also Castles et al., 1984). Although such migration might actually provide a source of sympathy or empathy for the Turkish candidacy as citizens of member states become more familiar with and connected to individuals from this group, this would require that EU citizens have had intimate contact with this group of migrants (e.g. in the form of friendships - see Jackman and Crane, 1986; Pettigrew, 1998; Wagner and Zick, 1995). In fact, most analyses of the relationship between high concentrations of immigrants or minorities and hostility to those groups indicates that the former is usually associated with hostility rather than with positive feelings or behaviours (Bobo, 1988; Giles and Hertz, 1994; Oliver and Mendelberg, 2000; Quillian, 1995; Taylor, 1998; Valenty and Sylvia, 2004). It is hypothesized that such hostility is likely to carry over into feelings about whether a country ought to be able to join the European Union, and that higher concentrations of Turkish migrants in a member state will mean individuals in that member state have a lower probability of supporting Turkey's candidacy.

It is possible, however, that the threat posed by migration from Turkey is also non-linear and functions through the perceived threats discussed 
above. Cross-level interactions are therefore investigated, with the following expectations:

- The combination of high levels of feelings of threat to group resources and high levels of Turkish migration will make EU citizens significantly more likely to oppose the Turkish candidacy.

- The combination of high levels of feelings of threat to group way of life and high levels of Turkish migration will make EU citizens significantly more likely to oppose the Turkish candidacy.

\section{Empirical analysis}

\section{Data and methods}

The statistical analysis proceeds as follows. I shall analyse each of the theoretical propositions presented above empirically in turn. In addition to the analysis of attitudes toward the Turkish candidacy, the study provides a comparison of these results with those for the Central and East European (CEE) candidates as well as Malta and Cyprus. In the absence of such an analysis, it would be unclear whether the findings presented here are unique to attitudes to Turkey or whether they also explain differences in opinion regarding other candidates. I thus base the empirical analyses on a somewhat less recent Eurobarometer, namely Eurobarometer (EB) 53 from spring 2000. Note also that I chose this particular survey because it contains measures of the theoretical propositions related to in-group protectiveness discussed above. ${ }^{4}$ However, these analyses fail to provide a completely adequate explanation of the potential uniqueness of the Turkish case; that is, the individuallevel explanations cannot account for the higher overall levels of opposition to the Turkish candidacy or for variation across countries in terms of opposition (see below). For this reason, I will look to the country level to improve the explanation of differences in opinion regarding Turkey's candidacy. ${ }^{5}$

Given that the results are pooled across EU member states ${ }^{6}$ and contextual variables are introduced, some corrective measures are necessary to account for the potential non-uniqueness of observations within countries. Thus, I use multi-level modelling techniques to correct for potentially biased standard errors and eventually to estimate the impact of context on attitudes to Turkey's candidacy. The reasons for using these particular techniques are now well explained in the literature on cross-national opinion formation (see Hooghe and Marks, 2004; Rohrschneider, 2002; Steenbergen and Jones, 2002; see also Raudenbush and Bryk, 2002, or Snijders and Bosker, 1999, for more 
general explanations of multi-level modelling techniques), but, very briefly, the potential for non-uniqueness may lead to the commitment of a Type I error (that is, rejecting the null hypothesis when the null is, in fact, true). Multi-level modelling techniques help to avoid this problem by re-computing standard errors based on the intra-class correlation (rho $)^{7}$ and the numbers of observations at different levels (e.g. individual and country levels). Because it is entirely possible that there is no significant clustering at the country level, it is important first to determine what the intra-class correlation is. Unfortunately, the response choices on the dependent variable in the current analysis are limited to 'in favour', 'oppose' and 'don't know', so standard variance components measures normally available for interval-scaled variables are inappropriate for this particular dependent variable. However, if the variable is converted into dichotomies and proportions across countries fitting into each category are compared, we may use ANOVA techniques to calculate rho. Ultimately, multinomial logistic regression is used to estimate the effects of independent variables on opposition to the Turkish candidacy, so I conduct the ANOVA in such a way that the dependent variable is as close as possible to the multinomial logistic regression scenario.

Table 3 provides the analysis of variance statistics for these categories of the dependent variable. Although the rho values are fairly small (e.g. only $5.6 \%$ of the individual-level variation in opposition to Turkish membership vis-à-vis support for Turkish membership can be accounted for by the crossnational variation in this variable), this coefficient is statistically significant and has a non-trivial impact on the effective number of observations. ${ }^{8}$ Thus, incorporating multi-level modelling techniques is clearly necessary.

Table 3 Opposition to Turkish EU membership: Analysis of variance

\begin{tabular}{|c|c|c|}
\hline & Sum of squares & Rho \\
\hline \multicolumn{3}{|c|}{ Oppose Turkish candidacy } \\
\hline Between groups & 157.48 & \\
\hline Within groups & 2625.53 & $.056 * *$ \\
\hline Total & 2783.01 & \\
\hline \multicolumn{3}{|c|}{ Uncertain about Turkish candidacy } \\
\hline Between groups & 56.93 & \\
\hline Within groups & 1834.61 & $.030 * *$ \\
\hline Total & 1891.54 & \\
\hline
\end{tabular}




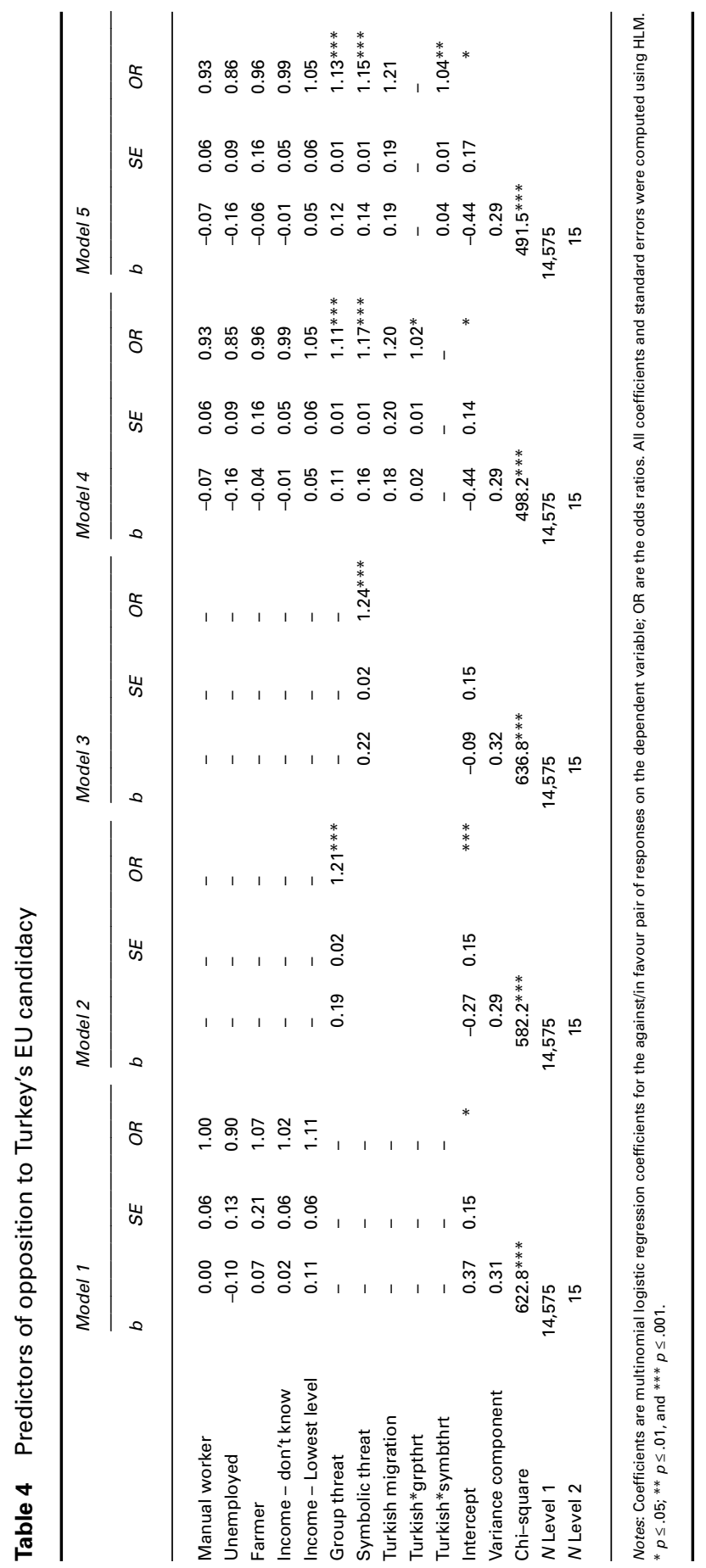




\section{Rational economic self-interest}

The specific hypotheses that follow from the above discussion of rational self-interest and opposition to the Turkish candidacy are that those doing manual labour, those who are farmers, those who are unemployed, and those at the lowest level of incomes ought to be less likely to support Turkey's EU candidacy than individuals in other occupation and income categories (Questions D15 and D29 in EB 53). Model 1 of Table 4 provides estimates of these effects based on a multinomial logistic regression analysis conducted using HLM software (recall that the dependent variable has three categories: support, oppose and don't know). Although the numbers of respondents in the 'don't know' category is non-trivial and may deserve further investigation, I focus here on the comparison between the 'in favour' and 'against' categories of the dependent variable, because the theories outlined above are devoted to explaining differences between these two groups. It is important to note that the analysis presented here is motivated by Achen's (2002) admonition against the 'kitchen sink' approach to model estimation; as argued by Achen, introducing too many control variables generally means that we are unable to adequately determine what is going on in a data set. Thus, for the purposes of this study, I will initially investigate the effects of key independent variables and then move to a multivariate analysis that includes the three key sets of independent variables discussed above (i.e. rational economic self-interest, threat to group resources, and threat to group culture and way of life).

Model 1 of Table 4 indicates that, even in a simple analysis that includes only measures of rational self-interest, these indicators do not achieve the basic minimum of statistical significance at the $p \leq .05$ level. Thus, in stark contrast to the expectations based on this approach, job status and income appear to have little bearing on hostility to Turkey's EU candidacy. Is this finding unique to the Turkish candidacy, however? Table 5 indicates that it may be: for each of the other pre-2004 candidates, at least one of the measures of rational self-interest achieves minimal statistical significance and, in almost every case, EU15 citizens at the lowest level of income are more likely to express hostility to the CEE candidates as well as to Cyprus and Malta. Moreover, the odds ratios indicate that the effects are substantively non-trivial in many cases. For instance, the odds of farmers in the EU15 opposing many of the candidacies (specifically the Czech, Slovak, Hungarian, Slovenian, Estonian, Latvian, Lithuanian, Bulgarian and Cypriot candidacies) is approximately 1.5 higher than the odds of their supporting these candidacies; the odds ratio for Malta is even larger, at 1.86. Also, the odds ratio of those at the lowest levels of income in the EU15 opposing the Czech, Slovak, Polish, 


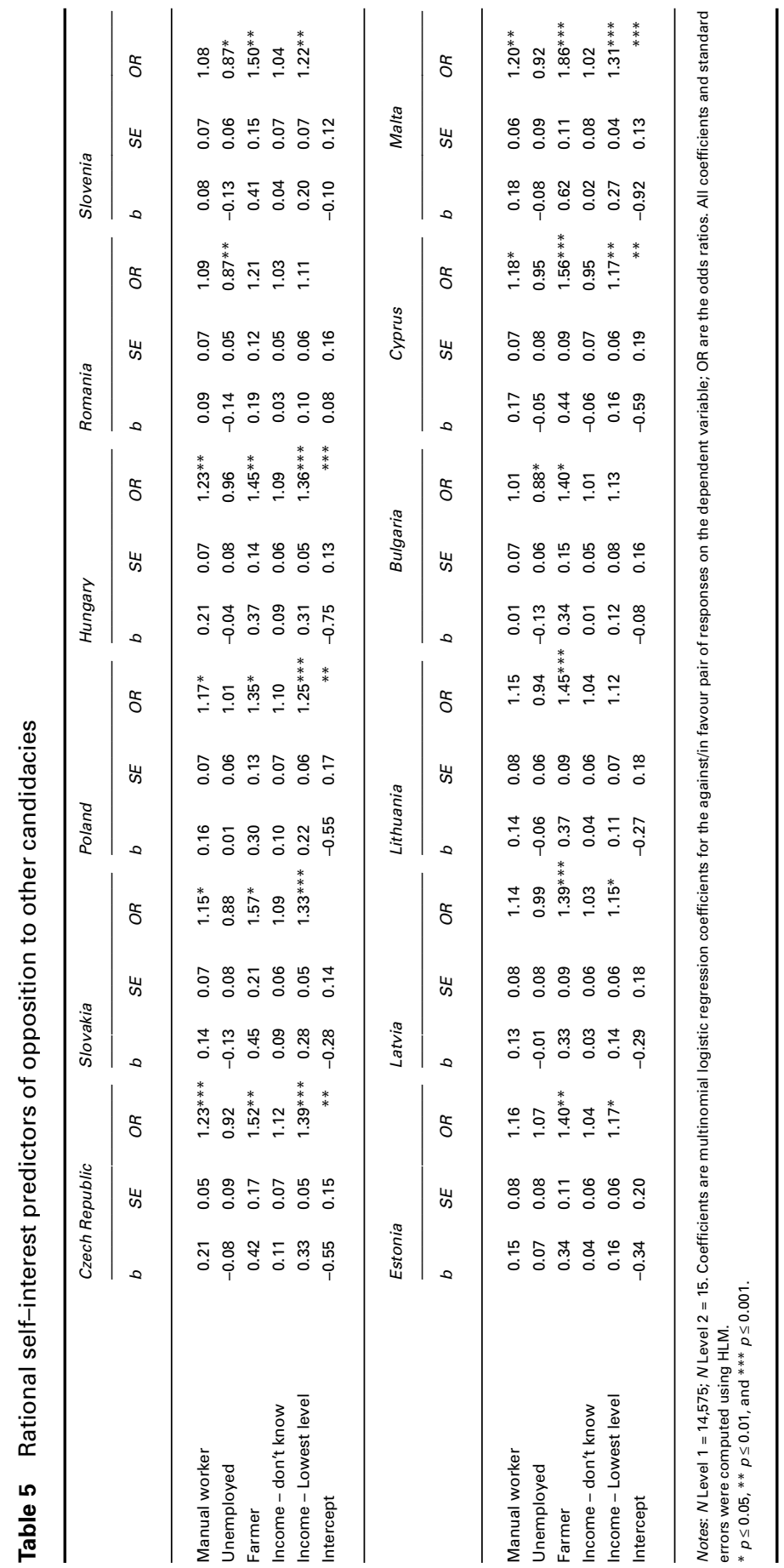


Hungarian and Maltese candidacies is 1.25 to 1.40 times that of not opposing. In sum, although economic self-interest may help us to distinguish between supporters and opponents of other candidates, it does not go far in explaining the opposition to Turkey's candidacy.

\section{Threats to group resources}

One of my key contentions in this paper is that opposition to Turkey's EU candidacy is likely to stem from worry about the effect of the country and its citizens on the general resources of at least one key in-group, the nation-state. This section utilizes an index consisting of the following three items to investigate the viability of this argument:

- 'In schools where there are too many children from these minority groups, the quality of education suffers (tend to agree, tend to disagree, don't know).' (Q51.1)

- 'People from these minority groups abuse the system of social benefits (tend to agree, tend to disagree, don't know).' (Q51.3)

- 'The presence of people from these minority groups increases unemployment in [COUNTRY] (tend to agree, tend to disagree, don't know).' (Q51.15)

'These minority groups' in this group of items refers to a previous survey question in which respondents were asked whether they feel themselves to belong to one of the minority groups in the country, in terms of race, religion and culture. Research indicates that, since the Second World War, respondents are generally referring to migrants when answering these questions (see McLaren, 2002).

These three items were chosen for their face value - they appear to tap into feelings about various resources that might be perceived as belonging to a key in-group, such as jobs, social welfare benefits and education benefits. Some may contend that these items actually capture fears of threat to one's own resources rather than to those of a larger in-group. Previous analyses by me (see, for instance, McLaren, 2006) indicate that this is highly unlikely, and that the above items do not, in fact, appear to be a reflection of personal self-interest.

Model 2 of Table 4 provides the multinomial logistic regression coefficients for the relationship between perceptions of threat to group resources and opposition to Turkey's candidacy. The results indicate that these perceptions are statistically significant predictors of such opposition. According to the odds ratio, a one unit increase in the index of threat to group resources 
(which ranges from 0 to 6 ) is associated with a 1.21 increase in the odds of opposing the Turkish candidacy. Clearly the impact is non-trivial as well as statistically significant.

Once again, we turn to the question of whether this explanation is unique to the Turkish candidacy. Does threat to the resources of the nation explain a particular fear of the Turkish candidacy or is it possible that feelings about other candidates are affected by such fears as well? Table 6 provides estimates of these effects and indicates that they have a very similar impact on opposition to all of the pre-2004 candidates. Thus, fears of threats to the nation-state's resources translate into opposition to the Turkish candidacy but also into opposition to any of these candidates (most of which have since joined the EU). Thus, we are still left with the question of whether there is any aspect to opposition to Turkey's candidacy that is unique to that particular candidate.

\section{Threats to culture and way of life}

Amongst the theories outlined above, threats to culture and way of life would be most likely to apply more exclusively to the Turkish case. As discussed

Table 6 Effect of perceived threats on opposition to other candidates

\begin{tabular}{|c|c|c|c|c|c|c|}
\hline & \multicolumn{3}{|c|}{ Threat to group resources } & \multicolumn{3}{|c|}{$\begin{array}{l}\text { Threat to group symbols, } \\
\text { way of life, etc. }\end{array}$} \\
\hline & $b$ & $S E$ & OR & $b$ & $S E$ & OR \\
\hline Czech Rep. & 0.24 & 0.02 & $1.27 * * *$ & 0.29 & 0.02 & $1.34 * * *$ \\
\hline Slovakia & 0.23 & 0.02 & $1.26 * * *$ & 0.28 & 0.02 & $1.62 * * *$ \\
\hline Poland & 0.22 & 0.02 & $1.25 * * *$ & 0.27 & 0.02 & $1.25^{* * *}$ \\
\hline Hungary & 0.22 & 0.02 & $1.24 * * *$ & 0.28 & 0.02 & $1.32 * * *$ \\
\hline Romania & 0.21 & 0.02 & $1.24 * * *$ & 0.24 & 0.02 & $1.27^{* * *}$ \\
\hline Slovenia & 0.22 & 0.02 & $1.25^{* * *}$ & 0.26 & 0.02 & $1.29 * * *$ \\
\hline Estonia & 0.21 & 0.02 & $1.24 * * *$ & 0.23 & 0.02 & $1.26^{* * *}$ \\
\hline Latvia & 0.20 & 0.02 & $1.23 * * *$ & 0.23 & 0.02 & $1.25^{* * *}$ \\
\hline Lithuania & 0.20 & 0.02 & $1.23 * * *$ & 0.22 & 0.02 & $1.25^{* * *}$ \\
\hline Bulgaria & 0.23 & 0.02 & $1.25^{* * *}$ & 0.25 & 0.02 & $1.25^{* * *}$ \\
\hline Cyprus & 0.20 & 0.02 & $1.27^{* * *}$ & 0.24 & 0.02 & $1.27^{* * *}$ \\
\hline Malta & 0.20 & 0.02 & $1.22 * * *$ & 0.25 & 0.02 & $1.28^{* * *}$ \\
\hline
\end{tabular}

Notes: $N$ Level $1=14,575, N$ Level $2=15$. Coefficients are multinomial logistic regression coefficients for the against/in favour pair of responses on the dependent variable; OR are the odds ratios. All coefficients and standard errors were computed using HLM.

*** $p \leq .001$. 
above, the key factor that distinguishes Turkey culturally is its religious roots, along with perceptions of backwardness or non-Europeanness with which these may be associated. That is, assumptions about the treatment of women and about the differences between European and Muslim culture generally would imply that perceived threats to culture and way of life predict opposition to Turkey's candidacy at much higher levels than they predict opposition to other candidates. An index including the following three items was used to gauge general feelings of threat to culture:

- 'People from these minority groups are enriching the cultural life of [COUNTRY] (tend to agree, tend to disagree, don't know; coding reversed prior to index construction).' (Q51.6)

- 'The religious practices of people from these minority groups threaten our way of life (tend to agree, tend to disagree, don't know).' (Q51.7)

- 'People belonging to these minority groups are so different, they can never be fully accepted members of [NATIONALITY] society (tend to agree, tend to disagree, don't know).' (Q59.11)

Again, these items were chosen for their face value. It must be noted that I am not contending that the sorts of threat measured by these three items are completely unrelated to perceived threats to group resources. That is, individuals who feel that there are threats to resources may also feel that minority groups pose threats to other, more symbolic aspects of in-group life. Indeed, the two constructs are correlated (Pearson's $r=.45$ ). However, I do contend that there is a theoretical distinction to be made, and indeed, as shown in Model 5 of Table 4, each construct also makes a unique contribution to understanding opposition to the Turkish candidacy.

Model 3 of Table 4 provides the multinomial logistic regression coefficient for the relationship between threats to culture and opposition to Turkey's EU membership. The size of the effect indicates that it has a very similar impact to that of perceived threat to group resources (the range of this scale is identical to the previous one, $0-6$ ).

Is the impact of this variable different when other candidates are considered? Table 6 indicates that fears of changes to national culture and way of life are associated with opposition to all of the pre-2004 candidates: fears stemming from a loss of culture clearly affect levels of hostility to Turkey's candidacy, but no more than they affect hostility to the other candidacies. Thus, the higher overall levels of opposition to Turkey's candidacy cannot be explained by individual-level perceptions of threat to culture and way of life. 


\section{The impact of context}

The findings thus far create an intriguing puzzle. If rational self-interest, threats to group resources and threats to culture and way of life do not provide a complete explanation for the relatively high level of hostility to Turkey's candidacy vis-à-vis other candidates, then it seems likely that the explanation for much of this hostility will lie in contextual-level variables. I discussed multiple potential contextual explanations in the theoretical section of this article. However, because of the very limited degrees of freedom at the level of country context (at the time of the survey used in this analysis, there were only 15 EU member states), these contending country-level explanations cannot all be entered into the analyses simultaneously.

Fortunately, it is possible to rule out many of these contending explanations for differences in levels of opposition to Turkey's candidacy. First, other empirical analyses have already pointed to the conclusion that the level of a candidate's economic development plays little or no role in explaining differing feelings about that candidate (Jones and van der Bijl, 2004; Karp and Bowler, 2006). Second, a simple scatterplot between levels of trade with Turkey and feelings about the Turkish candidacy indicates that this variable is not relevant when it comes to this particular candidacy. ${ }^{9}$ Finally, it seems highly unlikely that geographical proximity is positively connected with a 'we-feeling' when it comes to Turkey's candidacy. Greece is Turkey's immediate neighbour and is traditionally one of the country's strongest opponents; Austria and Germany are also amongst the closest EU countries to Turkey and their citizens are amongst the most hostile to the country's candidacy. On the other hand, the more distant EU member states such as the UK and Spain have citizens who are the least hostile to Turkey's candidacy (see Table 2 above). A simple scatterplot and regression analysis confirms that, if anything, the relationship between proximity and opposition to the Turkish candidacy is indeed the opposite of that predicted by Jones and van der Bijl (2004).

The final contextual hypothesis posited above was that a high level of concentration of Turkish migrants was likely to contribute to overall negative feelings about this particular candidacy. This hypothesis has two empirical implications: first, where the number of Turkish migrants is higher, the level of opposition to this candidacy will be higher; second, opposition to Turkey's candidacy across the EU (i.e. the EU average level of opposition) is higher because of the greater experience with Turks compared with immigrants from other candidate countries.

Figure 1 indicates that this contextual hypothesis generally receives empirical support. Even with the outliers - Germany and Austria - removed 


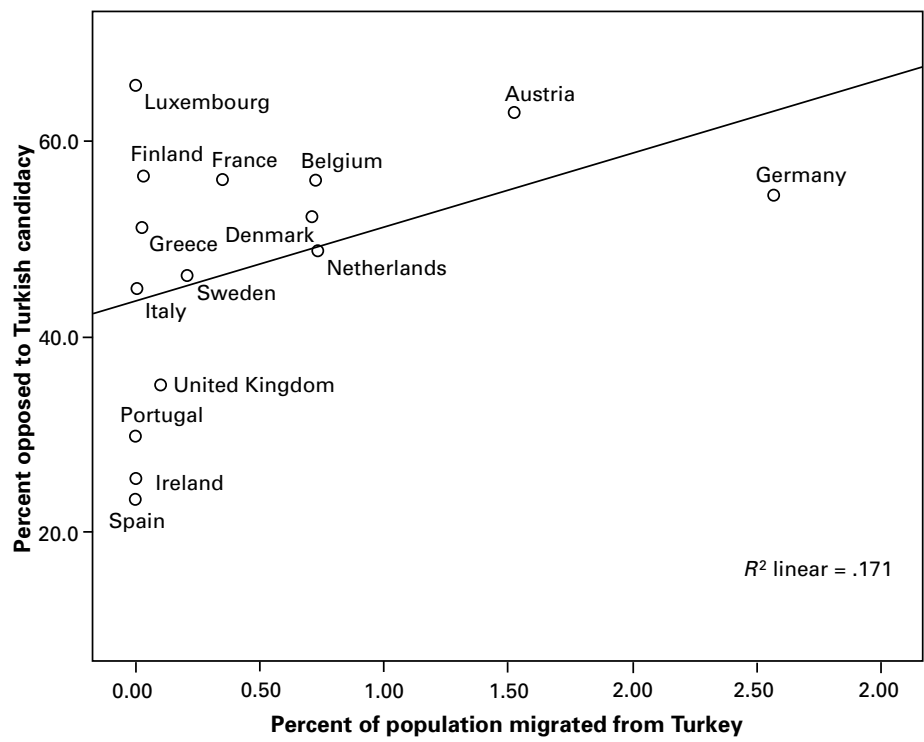

1a: All EU15 member states

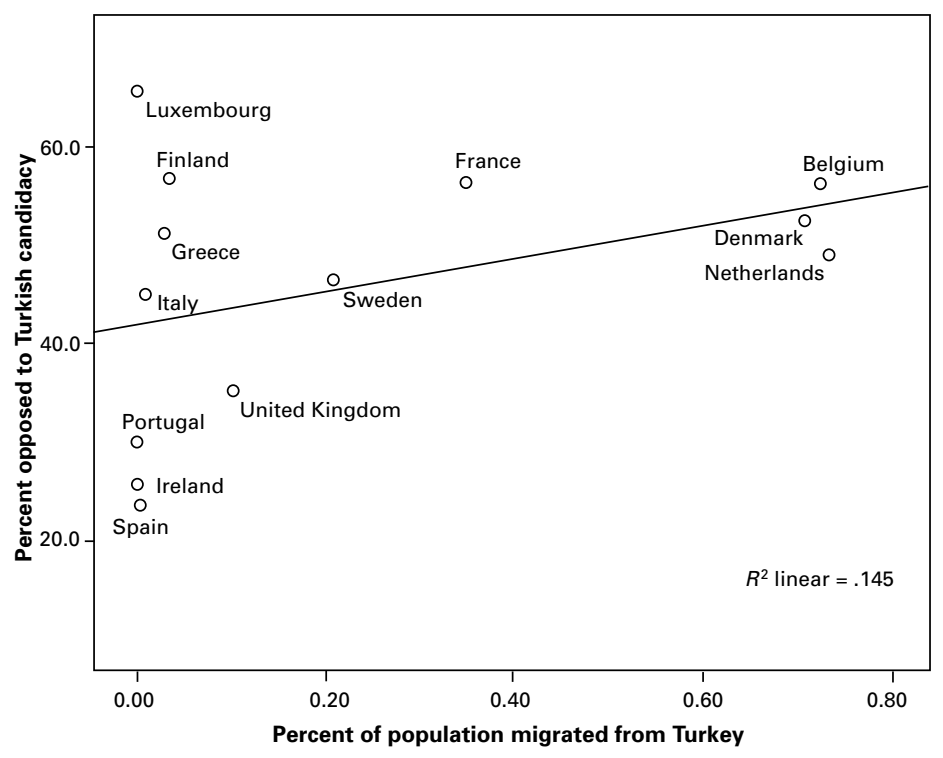

1b: Austria and Germany omitted

Figure 1 Migration and opposition to Turkey's EU candidacy.

Note: Migration measured using Eurostat's European Social Statistics: Migration, 2000 edition. 
from the scatterplot, the relationship remains positive and relatively strong (compare Figures 1a and 1b). ${ }^{10}$ This is in stark contrast to the other candidacies; for some of these (particularly Poland, the Czech Republic and Slovakia), although the relationship between migration and opposition to the candidacy is positive, the effect is weak and negative when Germany and Austria are omitted from the analysis. ${ }^{11}$

Figure 2 provides plots for the candidate for which the relationship was strongest, i.e. Poland. In addition to the fact that the effect of Polish migration is altered once Germany and Austria are omitted (whereas this was not the case for the Turkish candidacy), the generally smaller overall numbers of Polish migrants in relation to Turkish migrants should be noted (compare across the horizontal axes). It thus appears that high levels of Turkish migrants in several of the EU member states have created an atmosphere in which citizens of those countries are generally more negative about this candidacy than would be the case if the member state had not experienced migration from Turkey.

Models 4 and 5 of Table 4 also test for cross-level interactions, and the results indicate that the effect of migration may indeed be interactive. Figure 3 illustrates the effects of these interactions for Model 4, the model that includes group threat to resources. The interactive relationship between threat to culture and Turkish migration is very similar to that shown in Figure 3. Clearly both types of perceived threat affect the likelihood of opposing the Turkish candidacy but, when the level of migration from Turkey is high, general opposition to this candidacy is higher and increases even further when the perceived threat increases. The probability of opposing Turkey's candidacy is actually fairly low at low levels of perceived threat and when migration from Turkey is low to medium (the dashed lines in Figure 3); however, the probability of opposing the candidacy approaches .75 when the threat is high and when there are large numbers of Turkish migrants in the member state (the solid line in Figure 3). Again, a similar interactive effect could be detected in the case of Polish migration and the Polish candidacy; however, the predicted probability of opposing Poland's candidacy is far lower than the predicted probability of opposing Turkey's candidacy, and this appears to be related to the much smaller number of Polish migrants living in the EU15 member states. Thus, it seems that experience with Turkish migration, along with the high degrees of threat that may be associated with it, have made EU citizens more hostile to this candidate than to any other. The implication is that, if other candidates had been the source of such largescale migration into the EU, EU citizens might have been equally hostile to these candidates. 


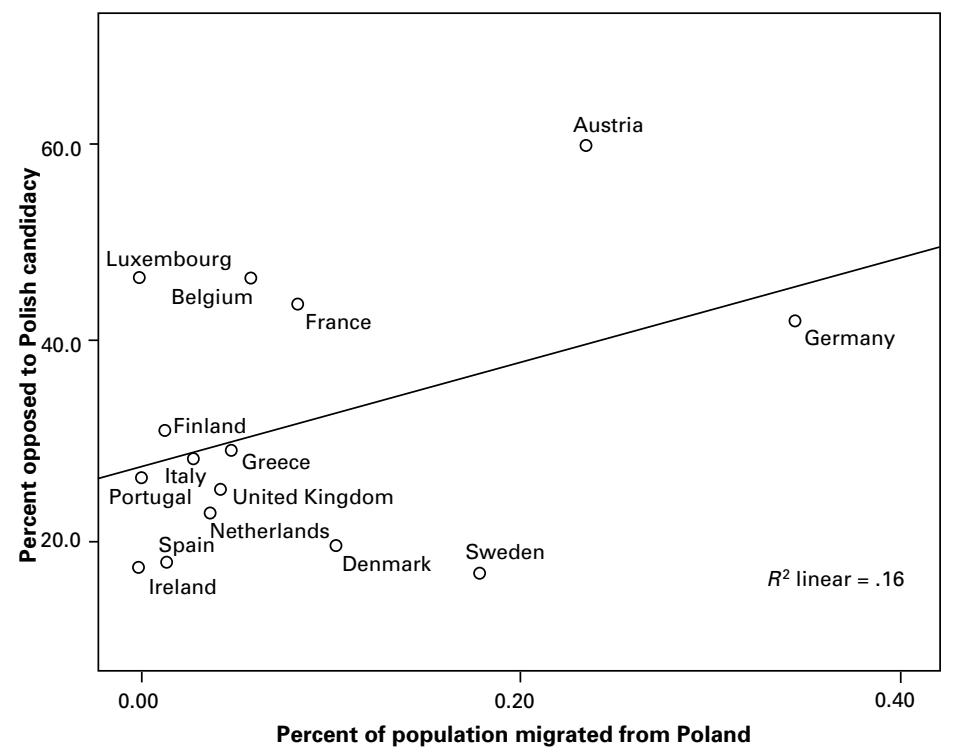

2a: All EU15 member states

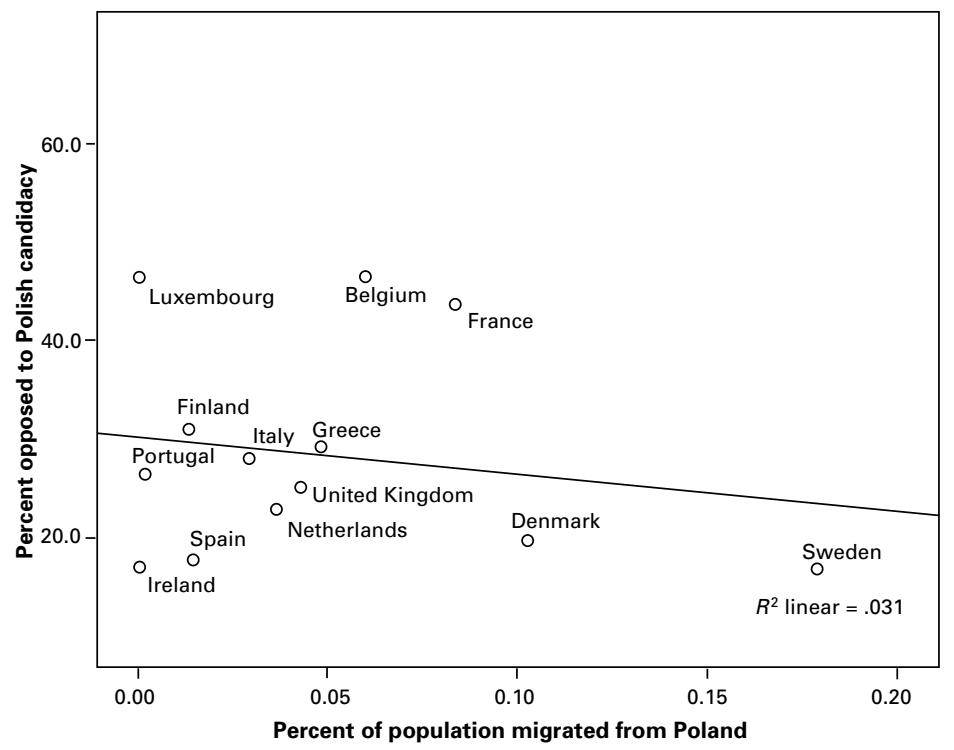

2b: Austria and Germany omitted

Figure 2 Migration and opposition to Poland's EU candidacy. 

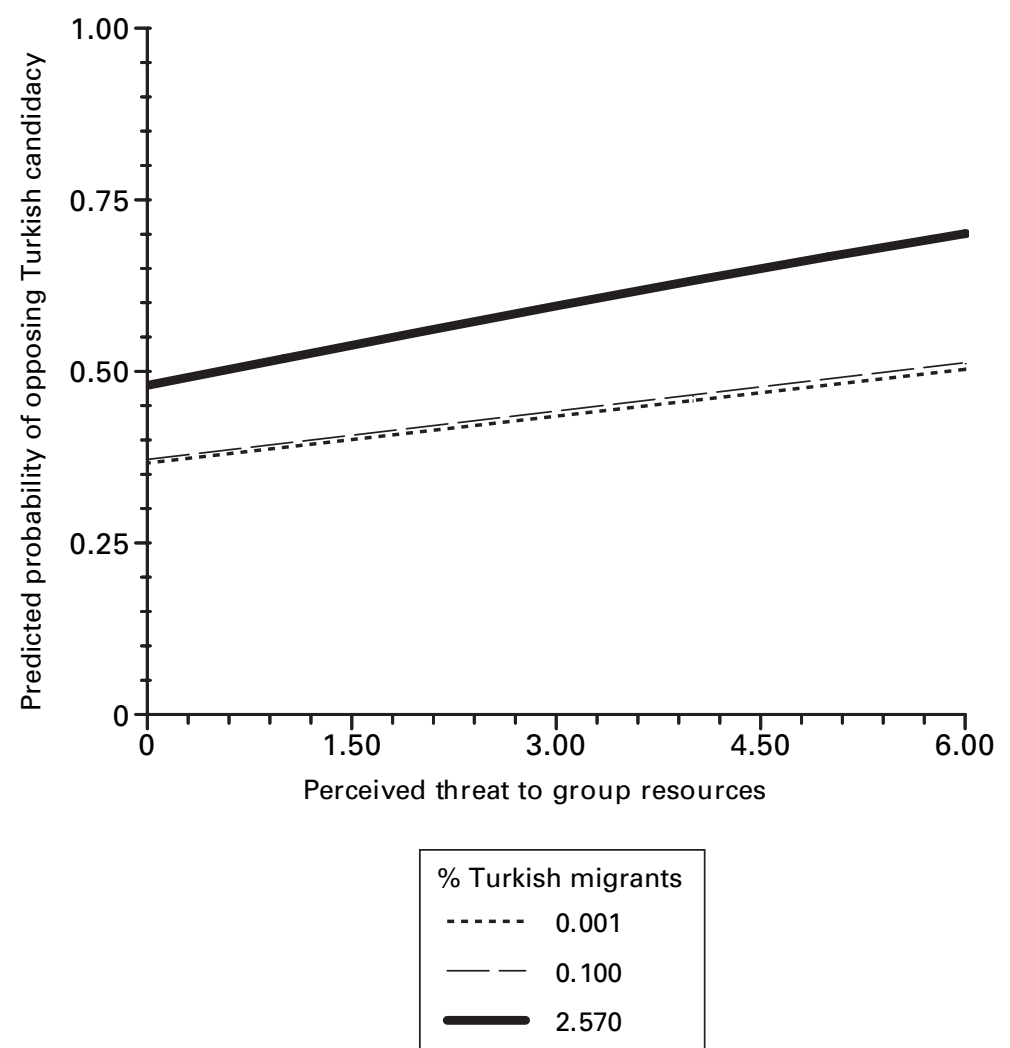

Figure 3 Interactive effect of perceived threat to group resources and Turkish migration.

Note: The three lines represent different levels of the population that are Turkish migrants, measured as a percentage of the total population of the EU member state. They are low, medium and high levels, defined as the countries in the 10th percentile, at the median, and in the 90th percentile, respectively. The percentages appear small compared with what might be expected, but they represent only documented migrants, not naturalized citizens or illegal immigrants.

\section{Conclusion}

I have presented opposition to Turkey's European Union candidacy in terms of two key themes: rational economic self-interest and perceived threat to group resources and way of life. The findings indicate that, whereas opposition to other candidacies may be connected to economic self-interest, in that those doing certain types of work and at lower income levels are more likely to oppose other candidacies, this does not appear to be the case for Turkey's candidacy. That is, those at varying income levels and occupations are equally 
opposed to the Turkish candidacy, and so rational economic self-interest does not go very far in helping to explain this opposition.

I then examined other potential threats posed by Turkey's EU candidacy. I argued that, because Turkey may be viewed in terms of its citizenry and the potential impact of this citizenry on the EU and its member states, theories of out-group hostility should be introduced. The first of these theories had to do with threats to group-level resources: although EU candidacies such as Turkey's may not necessarily be viewed in terms of personal economic losses, EU citizens may consider the potential losses to others like them, or their key in-groups. Similarly, I argued that the prospect of the Turkish candidacy might stimulate concerns that were less economic in nature and more 'symbolic' - i.e. threats to culture, way of life, and important symbols and values that the in-group holds to be dear.

In fact, the findings indicate that individual-level feelings of threat to group resources and culture are associated with a greater likelihood of opposing Turkey's candidacy, but they are also associated with a higher probability of opposing other pre-2004 candidates as well. That is, despite expectations to the contrary, high levels of perceived threat are not particularly associated with feelings about Turkey.

In order to further examine the potential for uniqueness of the Turkish case, I introduced the role of context. Economic interests in terms of trade with Turkey and other candidates appear to play very little role in predicting attitudes to this candidacy. On the other hand, the evidence presented indicates that experience with migration from Turkey may be a key contextual explanation for hostility to this candidacy. Instead of creating a 'we-feeling' and empathy for the Turkish candidacy, such migration appears to be having counterproductive effects. Two tentative implications are that (1) if the country had not been such a major sending country to the EU, opposition amongst EU citizens might not be so high, and (2) if the other candidates had been sources of such large-scale migration, opposition to those candidacies could have been far higher than it was.

Ultimately, the decision on a Turkish enlargement of the EU is the responsibility of EU member state leaders. However, it seems highly unlikely that these leaders will agree to admit Turkey in the face of large-scale mass opposition. Moreover, citizens in many of the member states are demanding a referendum on the issue and if a referendum is held in a country such as France it appears very unlikely that citizens will vote in favour of Turkey's entry into the EU. This paper has provided some tools with which government leaders may try to alter citizen opinion on this issue. Clearly, citizens are most worried about the potential effects of Turkish entry on the economic and social welfare benefits of their fellow citizens and on national culture and 
way of life, as they were with other candidates. The difference, however, is that large-scale migration from Turkey may have created an environment in which these fears are amplified to a much greater extent than was the case with the 2004 enlargement candidates. If government leaders are going to successfully enlarge the EU to include this prospective member state, particularly given the degree of experience with Turkish migration, they will need to adopt measures to allay such fears, perhaps including provision for a waiting period on the free movement of labour provision similar to that adopted in the 2004 enlargement. Turkish leaders are likely to strongly oppose such measures, but the findings presented here indicate that they must recognize that their citizens are perceived as threatening and that the EU may need some time to adjust to having the country as a full EU member state.

\section{Notes}

I wish to thank three EUP reviewers for providing extremely helpful comments on earlier versions of this paper. Any errors are, of course, my sole responsibility.

1 For instance, the average monthly private sector wage in Turkey in 1999 was approximately $€ 500$ (see http://www.dol.gov/ilab/media/reports/oiea/ wagestudy/FS-Turkey.htm, consulted 12 June 2006) whereas the average German monthly wage in 1999 was €2340, with the eastern part of Germany still having an average wage of $€ 1728$ (see http:/ / www.destatis.de/ indicators/e/lrver03ae.htm, consulted 12 June 2006).

2 Although the earliest post-war migrants tended to be relatively skilled and educated and from the more developed regions vis-à-vis the average population in Turkey, in the second half of the 1960s recruitment switched to less skilled rural workers (see Gökdere, 1978).

3 The choice of nation as the key in-group here is in great part related to the paucity of data concerning feelings of protectiveness of other levels of ingroups (particularly in surveys that also measure attitudes to EU enlargement). However, data from the 1995 International Social Survey Programme and Eurobarometer surveys indicate that the focus on the nation as a key ingroup is not unreasonable: national pride in things such as the way democracy works in the country, scientific achievements, sports, the arts and history is generally high in Europe, and approximately $90 \%$ of EU citizens claim to feel attached to their country (see, for instance, Eurobarometer 54.1 for the latter statistics).

4 Namely, the items listed in the sections on 'Threat to Group Resources' and 'Threat to Symbols, Culture, Way of Life' are available in only a handful of Eurobarometer polls (and cross-national polls about enlargement generally appear only in the Eurobarometer series). The most recent of these that includes questions about threats from minorities is EB 59.2 from spring 2003, but this poll does not include items measuring threat to group resources nor does it include items about enlargement. 
5 I focus upon the country-level context because of the considerable crossnational differences in opposition to Turkey's candidacy illustrated in Table 2. Moreover, immigration policies are determined by national governments, and so it is assumed that country-level immigration sets the tone of debate regarding immigration. Other contexts, such as neighbourhood, could also be analysed, except for the paucity of comparable data across EU member states.

6 The member states in the EU at the time of the survey used here were: Austria, Belgium, Denmark, Finland, France, Germany, Greece, Ireland, Italy, Luxembourg, the Netherlands, Portugal, Spain, Sweden and the United Kingdom.

7 Rho can be thought of as the proportion of variance in a variable that can be attributed to the units on which the sample is based (e.g. country); it is the variance at this level divided by the total variance in the variable (see Goldstein, 1987).

8 If we assume a sample size of 1000 across 15 countries with a rho value of 5.6, the effective number of observations for the 'oppose Turkish candidacy' / 'support Turkish candidacy' variable is less than 300. Also note that, if the variables were dichotomized such that, for the oppose variable, against $=1$ and all else $=0$, and, for the don't know variable, don't know $=1$ and all else $=0$, rho values are very similar to those reported here $(0.060$ and 0.034 , respectively).

9 All plots and analyses not presented here can be found on the EUP website. See http://www.uni-konstanz.de/eup/issues.htm.

10 When using multi-level modelling techniques, the effect of migration from Turkey on hostility to the Turkish candidacy is statistically significant as well.

11 The full range of scatterplots is available on the EUP website.

\section{References}

Achen, Christopher (2002) 'Toward a New Political Methodology', Annual Review of Political Science 5: 423-50.

Ahtisaari, Martti, Kurt Biedenhopf, Emma Bonino, Hans van den Broek, Bronislaw Geremek, Anthony Giddens, Marcelino Oreja Aguirre, Michel Rocard and Albert Rohan (2004) 'Turkey in Europe: More Than a Promise?', URL (consulted 12 June 2006): http:/ / www.independentcommissiononturkey.org/ pdfs/english.pdf.

Anderson, Christopher J. (1998) 'When in Doubt, Use Proxies: Attitudes toward Domestic Politics and Support for European Integration', Comparative Political Studies 31(5): 569-601.

Anderson, Christopher J. and M. Shawn Reichert (1996) 'Economic Benefits and Support for Membership in the EU: A Cross-National Analysis', Journal of Public Policy 15(3): 231-49.

Bobo, Lawrence (1988) 'Group Conflict, Prejudice, and the Paradox of Contemporary Racial Attitudes', in Phyllis A. Katz and Dalmas Taylor (eds) Eliminating Racism: Profiles in Controversy, pp. 85-114. New York: Plenum Press. 
Brinegar, Adam P. and Seth K. Jolly (2005) 'Location, Location, Location: National Contextual Factors and Public Support for European Integration', European Union Politics 6(2): 155-80.

Castles, S., B. Heather and T. Wallace (1984) Here for Good: Western Europe's New Ethnic Minorities. London: Pluto Press.

Chong, Dennis, Jack Citrin and Patricia Conley (2001) 'When Self-Interest Matters', Political Psychology 22(3): 541-70.

Cichowski, Rachel A. (2000) 'Western Dreams, Eastern Realities - Support for the European Union in Central and Eastern Europe', Comparative Political Studies 33(10): 1243-78.

Citrin, Jack, Donald P. Green, Christopher Muste and Cara Wong (1997) 'Public Opinion toward Immigration Reform: The Role of Economic Motivations', Journal of Politics 59(3): 858-81.

Eichenberg, Richard C. and Russell J. Dalton (1993) 'Europeans and the European Community: The Dynamics of Public Support for European Integration', International Organization 47(4): 507-34.

Eralp, Atila (1993) 'Turkey and the EC in a Changing Post-War International System', in Canan Balkir and Allan M. Williams (eds) Turkey and Europe, pp. 23-44. London and New York: Pinter.

Funk, Carolyn L. and Patricia A. Garcia-Monet (1997) 'The Relationship between Personal and National Concerns in Public Perceptions about the Economy', Political Research Quarterly 50(2): 317-43.

Gabel, Matthew (1998a) Interests and Integration: Market Liberalization, Public Opinion, and the European Union. Ann Arbor: University of Michigan Press.

Gabel, Matthew (1998b) 'Economic Integration and Mass Politics: Market Liberalization and Public Attitudes in the European Union', American Journal of Political Science 42(2): 936-53.

Gelissen, John (2000) 'Popular Support for Institutionalised Solidarity: A Comparison between European Welfare States', International Journal of Social Welfare 9(4): 285-300.

Gevers, Josette, John Gelissen and Wil Arts (2000) 'Public Health Care in the Balance: Exploring Popular Support for Health Care Systems in the European Union', International Journal of Social Welfare 9(4): 301-21.

Giles, Michael and Kaenan Hertz (1994) 'Racial Threat and Partisan Identification', American Political Science Review 88(2): 317-26.

Gökdere, Y. Ahmet (1978) Yabanci Ülkelere Isgücü Akimi ve Türk Ekonomisi Üzerindeki Etkileri. Ankara: Is Bankasi Yayinlari.

Goldstein, Harvey (1987) Multilevel Models in Educational and Social Research. Oxford: Oxford University Press.

Hooghe, Liesbet and Gary Marks (2004) 'Does Identity or Economic Rationality Drive Public Opinion on European Integration?', PS: Political Science and Politics 37(3): 415-20.

Ivarsflaten, Elisabeth (2005) 'Threatened by Diversity: Why Restrictive Asylum and Immigration Policies Appeal to Western Europeans', Journal of Elections, Public Opinion and Parties 15(1): 21-45.

Jackman, Mary R. and Marie Crane (1986) "'Some of My Best Friends are Black ...": Interracial Friendship and Whites' Racial Attitudes', Public Opinion Quarterly 50(4): 459-86. 
Jones, Erik and Niels van der Bijl (2004) 'Public Opinion and Enlargement: A Gravity Approach', European Union Politics 5(3): 331-51.

Karp, Jeffrey A. and Shaun Bowler (2006) 'Broadening and Deepening or Broadening versus Deepening: The Question of Enlargement and Europe's "Hesitant Europeans"', European Journal of Political Research 45(3): 369-90.

Kinder, Donald R. (1981) 'Presidents, Prosperity, and Public Opinion', Public Opinion Quarterly 45(1): 1-21.

Kinder, Donald R. and D. Roderick Kiewiet (1979) 'Economic Discontent and Political Behavior: The Role of Personal Grievances and Collective Economic Judgments in Congressional Voting', American Journal of Political Science 23(3): 495-527.

LeVine, Robert A. and Donald T. Campbell (1972) Ethnocentrism: Theories of Conflict, Ethnic Attitudes, and Group Behaviour. New York: Wiley.

Lewis-Beck, Michael S. (1988) Economics and Elections: The Major Western Democracies. Ann Arbor: University of Michigan Press.

McLaren, Lauren M. (2002) ‘Public Support for the European Union: Cost/Benefit Analysis or Perceived Cultural Threat?', Journal of Politics 64(12): 551-66.

McLaren, Lauren M. (2006) Identity, Interests and Attitudes to European Integration. Houndmills: Palgrave Macmillan.

Mahler, Vincent A., Bruce J. Taylor and Jennifer R. Wozniak (2000) 'Economics and Public Support for the European Union: An Analysis at the National, Regional, and Individual Levels', Polity 32(3): 429-53.

Mansbridge, Jane J. (ed.) (1990) Beyond Self-Interest. Chicago, IL: University of Chicago Press.

Markowski, Radoslaw and Joshua A. Tucker (2005) 'Pocketbooks, Politics, and Parties: The 2003 Polish Referendum on EU Membership', Electoral Studies 24(3): 409-33.

Müftüler-Baç, Meltem (1997) Turkey's Relations with a Changing Europe. Manchester: Manchester University Press.

Müftüler-Baç, Meltem (2000) 'Through the Looking Glass: Turkey in Europe', Turkish Studies 1(1): 21-35.

Oliver, J. Eric and Tali Mendelberg (2000) 'Reconsidering the Environmental Determinants of White Racial Attitudes', American Journal of Political Science 44(3): 574-89.

Pettigrew, Thomas F. (1998) 'Intergroup Contact Theory', Annual Review of Psychology 49: 65-85.

Quillian, Lincoln (1995) 'Prejudice as a Response to Perceived Group Threat: Population Composition and Anti-Immigrant and Racial Prejudice in Europe', American Sociological Review 60(4): 586-611.

Raudenbush, Stephen W. and Anthony S. Bryk (2002) Hierarchical Linear Models: Applications and Data Analysis Methods, 2nd edn. Newbury Park, CA: Sage.

Rohrschneider, Robert (2002) 'The Democracy Deficit and Mass Support for an EU-Wide Government', American Journal of Political Science 46(2): 463-75.

Sears, David O. and Carolyn Funk (1990) 'Self-Interest in Americans' Political Opinions', in Jane Mansbridge (ed.) Beyond Self-Interest, pp. 147-70. Chicago, IL: University of Chicago Press.

Sears, David O. and Richard R. Lau (1983) 'Indicating Apparently Self-Interested Political Preferences', American Journal of Political Science 27(2): 223-52. 
Sears, David O., Carl P. Hensler and Leslie K. Speer (1979) 'Opposition to Busing: Self-Interest or Symbolic Racism?', American Political Science Review 73(2): 369-84.

Slomczynski, Kazimierz M. and Goldie Shabad (2003) 'Dynamics of Support for European Integration in Post-Communist Poland', European Journal of Political Research 42(4): 503-39.

Sniderman Paul M., Louk Hagendoorn and Markus Prior (2004) 'Predisposing Factors and Situational Triggers: Exclusionary Reactions to Immigrant Minorities', American Political Science Review 98(1): 35-49.

Snijders, Tom A. and Roel Bosker (1999) Multilevel Analysis: An Introduction to Basic and Advanced Multilevel Modeling. London: Sage Publications.

Steenbergen, Marco R. and Brad S. Jones (2002) 'Modeling Multilevel Data Structures', American Journal of Political Science 46(1): 218-37.

Taylor, Marylee (1998) 'How White Attitudes Vary with the Racial Composition of Local Populations: Numbers Count', American Sociological Review 63(4): $56-78$.

US State Department (2005) 'Country Study: Turkey', URL (consulted 12 June 2006): http://lcweb2.loc.gov/frd/cs/trtoc.html.

Valenty, Linda O. and Ronald D. Sylvia (2004) 'Thresholds for Tolerance: The Impact of Racial and Ethnic Population Composition on the Vote for California Propositions 187 and 209', Social Science Journal 41(3): 433-46.

Wagner, Ulrich and Andreas Zick (1995) 'The Relation of Formal Education to Ethnic Prejudice: Its Reliability, Validity, and Explanation', European Journal of Social Psychology 25(1): 41-56.

\section{About the author}

Lauren M. McLaren is Associate Professor of Politics, University of Nottingham, School of Politics and International Relations, Nottingham NG7 2RD, UK.

Fax: +44 1159514859

E-mail: lauren.mclaren@nottingham.ac.uk 